\title{
An Inelastic Neutron Scattering Investigation of the Temporal Behaviour of the Hydrocarbonaceous Overlayer of a Prototype Fischer-Tropsch to Olefins Catalyst
}

\author{
Alisha L. Davidson ${ }^{1} \cdot$ Paul B. Webb ${ }^{2} \cdot$ Stewart F. Parker ${ }^{3} \cdot$ David Lennon $^{1}[$
}

Accepted: 25 February 2021 / Published online: 17 March 2021

(c) The Author(s) 2021

\begin{abstract}
A dual sodium and sulfur promoted haematite, representative of a candidate Fischer-Tropsch to olefins (FTO) catalyst, is prepared and contrasted with the performance of an unpromoted hematite sample in the ambient pressure CO hydrogenation reaction at $623 \mathrm{~K}$ as a function of time-on-stream $(0-24 \mathrm{~h})$. In-situ post-reaction temperature-programmed oxidation measurements show the carbon evolutionary phase of the catalyst conditioning process to be retarded for the FTO catalyst. Ex-situ inelastic neutron scattering measurements show the promoters perturb the formation of a previously described hydrocarbonaceous overlayer. Specifically, whilst the $\mathrm{sp}^{3}$ hybridised $\mathrm{C}-\mathrm{H}$ modes of the hydrocarbonaceous overlayer are almost unaffected by the additives, the formation of the overlayer's sp ${ }^{2}$ hybridised $\mathrm{C}-\mathrm{H}$ modes are noticeably impeded. The results are discussed in terms of the $\mathrm{Na} / \mathrm{S}$ promoters disturbing the formation of an ordered hydrocarbonaceous overlayer that is thought to constrain the supply of adsorbed hydrogen atoms, which favours the formation of unsaturated hydrocarbons associated with the FTO process.
\end{abstract}

Keywords Fischer-Tropsch to olefins catalysis · Inelastic neutron scattering · Temperature-programmed oxidation

\section{Introduction}

Fischer-Tropsch synthesis (FTS) is a well-established process for the conversion of carbon sources (coal, gas or biomass) into relatively large molecular weight saturated hydrocarbons. Subsequent hydro-treating of the complex product slate provides access to a range of useful hydrocarbons, for example sulfur-free diesel or aviation fuel. The FTS process is heterogeneously catalysed, with iron or cobalt based catalysts finding wide application in numerous large-scale FTS operations located throughout the world. The topic of

Paul B. Webb

pbw@st-andrews.ac.uk

David Lennon

David.Lennon@glasgow.ac.uk

1 School of Chemistry, Joseph Black Building, University of Glasgow, Glasgow G12 8QQ, UK

2 School of Chemistry, University of St Andrews, Purdie Building, St Andrews KY16 9ST, UK

3 ISIS Facility, STFC Rutherford Appleton Laboratory, Chilton, Didcot, Oxon OX11 0QX, UK
FTS chemistry has been comprehensively reviewed by Van de Loosdrecht et al. [1].

A distinct variant of FTS that has recently come to the fore is the Fischer-Tropsch-to-olefins (FTO) process. Here, modified iron-based catalysts are employed that switch the product slate away from long chain saturated hydrocarbons towards short chain olefins [2-15]. Given that low molecular weight olefins constitute the chemical building blocks for the chemical manufacturing industry, there is an increasing interest in FTO chemistry. Although FTO catalysis is a relatively new field, there is an approaching consensus of what constitutes a viable FTO catalyst. Namely, starting from a hematite foundation usually associated with classic FTS chemistry, the inclusion of a Group I cation (e.g. sodium or potassium) with a relatively small concentration of sulfur as chemical promoters is reported to enhance the selectivity to high value $\mathrm{C}_{2}-\mathrm{C}_{4}$ olefins [2-15]. Moreover, this combination of additives may additionally reduce methane yields [2-4]. The topic of FTO catalysis has recently been reviewed by Wyckenhusen and Partall [7-9].

A body of work from the authors has used the technique of inelastic neutron scattering (INS) to investigate a range of iron-based FTS catalysts, with particular attention being 
paid to the catalyst conditioning phase [16-23]. The application of INS is beneficial, as it provides a means of obtaining the vibrational spectrum $\left(50-4000 \mathrm{~cm}^{-1}\right.$ in favourable circumstances) of the catalyst after a range of process operations [24, 25]. An advantage of INS applied in this way is that the process of carbon laydown, commonly encountered with heterogeneous catalysts, does not interfere with spectral acquisition, as can often be the case with optical spectroscopic techniques such as infrared spectroscopy [26]. A principal output from that body of work on FTS related surface chemistry is the realisation that, in addition to contributions from iron oxides, iron carbides, iron, amorphous carbon and graphite, the active phase of the FTS catalyst matrix is additionally comprised of a hydrocarbonaceous overlayer [16-21]. Moreover, it is proposed that this overlayer resides above a domain of Hägg carbide $\left(\mathrm{Fe}_{5} \mathrm{C}_{2}\right)$ that has the capacity for dissociative adsorption of carbon monoxide and dihydrogen. The overlayer is thought to act as a template that controls the reagents' access to the underlying carbide, with the active site representing a pocket within the hydrocarbonaceous overlayer [20]. Crucially, this arrangement supports an efficient supply of adsorbed hydrogen atoms to the active sites, a process which favours saturated products.

These INS based investigations of FTS surface chemistry have been broadened to include an examination of a range of FTO catalyst formulations. In the first instance, this involved solely sulfur promoted hematite catalysts [22] but, recently, a range of doubly promoted $\mathrm{Na}$ and $\mathrm{S}$ modified hematite catalysts have been examined [23]. Following favourable FTO product profiles reported by Botes et al. [2], a conventional hematite catalyst was promoted with $\sim 2000 \mathrm{ppm}$ of sodium, whilst the sulfur promotion was examined over the range 0-250 ppm [23]. Using ambient pressure $\mathrm{CO}$ hydrogenation at $623 \mathrm{~K}$ as a test reaction, INS showed the formation of a hydrocarbonaceous overlayer to be significantly attenuated by the presence of the promoters, with increasing $\mathrm{S}$ levels significantly reducing the intensity of the $\mathrm{sp}^{2}$ and $\mathrm{sp}^{3}$ hybridised $v(\mathrm{C}-\mathrm{H})$ modes of the overlayer, albeit to differing degrees. Extending the hydrogen supply considerations outlined above for FTS catalysts [20,21], it was proposed that, via preventing coherent ordering of a hydrocarbonaceous overlayer, the sulfur was constraining the supply of surface hydrogen relative to carbon. This effect could be coupled to a role for the sodium, which enhances the supply of carbon via facile $\mathrm{CO}$ dissociation. This scenario potentially provides an explanation for why dual promotion is more amenable for inducing FTO surface chemistry [23].

The INS measurements of the FTO catalysts were recorded after the doped catalysts had experienced a fixed reaction time of $8 \mathrm{~h}$ (ambient pressure $\mathrm{CO}$ hydrogenation at $623 \mathrm{~K}$ ). Experience with unpromoted iron-based FTS catalysts has highlighted the importance of temporal trends that are linked in to the well-documented 'evolutionary' phase of iron-based FTS catalyst [27]. For example, Warringham et al.. used INS to examine a unpromoted hematite over a period of $24 \mathrm{~h}$ time-on-stream (T-o-S) [20]. Subsequently, Davidson et al.. extended this period to $240 \mathrm{~h} \mathrm{~T}-\mathrm{o}-\mathrm{S}$. Crucially, the latter work showed the intensity of the $\mathrm{C}-\mathrm{H}$ stretching mode of the $\mathrm{sp}^{3}$ hybridised component of the hydrocarbonaceous overlayer saturated at about $24 \mathrm{~h} \mathrm{T-o-}$ $\mathrm{S}$, whilst the corresponding intensity of the $\mathrm{C}-\mathrm{H}$ stretching mode of the $\mathrm{sp}^{2}$ hybridised component required 100-200 $\mathrm{h}$ T-o-S to achieve saturation. Furthermore, temperature-programmed oxidation measurements showed temporal trends for the formation of surface carbonaceous entities [21]. Against this background, it is timely to examine temporal trends in FTO catalysts.

This work will examine a candidate FTO catalyst and benchmark its performance against an unpromoted hematite catalyst that has been examined previously, designated as Fe-ref [20, 21]. The FTO catalyst selected was mid-range from the series of FTO catalysts previously examined [23]: hematite $+2000 \mathrm{ppm} \mathrm{Na}+100 \mathrm{ppm} \mathrm{S}$, designated as Fe-Na$\mathbf{S}_{\mathbf{1 0 0}}$. Performance characteristics for Fe-Na-S $\mathbf{S}_{\mathbf{1 0 0}}$ are as follows (Fe-ref values in parentheses). FT activity based on $\mathrm{CO}$ conversion that excludes $\mathrm{CO} \rightarrow \mathrm{CO}_{2}$ production: 47.9 (78.5) $\mu \mathrm{mol} \mathrm{g} \mathrm{g}^{-1} \mathrm{~s}^{-1}$; methane production: 9.0 (24.9) \%; $\mathrm{C}_{2}-\mathrm{C}_{4}$ olefin selectivity: 31 (15) \%; mean $\mathrm{C}_{2}-\mathrm{C}_{4}$ olefin : paraffin ratio $8.2(0.7)$ [23]. Section 3.1 presents post-reaction TPO profiles for 3-24 h T-o-S, whilst Sect. 3.2 presents the INS spectra $\left(400-4000 \mathrm{~cm}^{-1}\right)$ over the same period. Comparisons between the profiles of $\mathbf{F e}-\mathbf{N a}-\mathbf{S}_{\mathbf{1 0 0}}$ versus $\mathbf{F e}$-ref are informative and, indeed, reveal the presence of temporal trends in FTO catalysis. With reference to recently refined assignments for post-reaction TPO data of FTS catalysts [21], connectivity between active carbon species, surface carbon and the $\mathrm{sp}^{2}$ hybridised component of the hydrocarbonaceous overlayer is proposed.

\section{Experimental}

\subsection{Catalyst Preparation}

The catalyst under investigation within this study was an unsupported hematite catalyst, dually promoted with sulfur [100 ppm] and sodium [2000 ppm] (sample code: Fe-Na$\mathbf{S}_{\mathbf{1 0 0}}$ ), the characterisation of which is described elsewhere [23]. The preparative procedure utilised a batch reactor [19, 20]. The preparative method firstly involved the co-precipitation of iron nitrate (Sigma Aldrich, 99.99\%) and sodium carbonate (Sigma Aldrich, 99.99\%), followed by a filtration and washing step. If calcined at this stage, a hematite $\left(\alpha-\mathrm{Fe}_{2} \mathrm{O}_{3}\right)$ catalyst in the absence of promoters/modifiers (sample code: Fe-ref) is produced. The unpromoted, Fe-ref catalyst has been an area of investigation previously [17-21] 
and comparisons to this catalyst are made within the current study. For the doubly promoted sample $\left(\mathbf{F e}-\mathbf{N a}-\mathbf{S}_{\mathbf{1 0 0}}\right)$, the same preparative method for Fe-ref was followed but with the addition of a slurry step to incorporate the promoters into the catalyst after the filtering and washing steps. This involved the addition of a fixed amount of ammonium sulfate (Sigma Aldrich, 99.99\%) and sodium carbonate dissolved in $20 \mathrm{ml}$ of deionised water. The sample was calcined using the same procedure as the un-promoted sample, Fe-ref, and ground and sieved to a particle size range of $250-500 \mu \mathrm{m}$.

\subsection{Micro-Reactor Measurements}

The reaction testing was performed at ambient pressure using a catalyst test line composed of $1 / 8$ in. diameter stainless steel Swagelok tubing, a description of which can be found elsewhere $[19,20]$. The catalyst was loaded into a $1 / 4$ in. quartz tube reactor and plugged with quartz wool. The reactor was housed within a tube furnace (Carbolite MTF 10/15/30) equipped with PID control. A thermocouple was positioned within the catalyst bed to ensure accurate temperature readings during measurement. $\mathrm{CO}$ hydrogenation conditions were established over the bypass (CO: $3.91 \mathrm{ml} \mathrm{min}^{-1}$, CK Gas, $99.8 \%$; $\mathrm{H}_{2}: 7.93 \mathrm{ml} \mathrm{min}^{-1}$, BOC Ltd, $99.8 \%$; He: $24.0 \mathrm{ml} \mathrm{min}{ }^{-1}$, BOC Ltd, $99.9 \%$ ) before introduction to the catalyst reactor (total weight hourly space velocity (WHSV) of $13.63 \mathrm{~h}^{-1}$ ). All gas flows were monitored using an in-line quadrupole mass spectrometer (Hiden Analytical, HPR-20) attached to the reactor exit line via a differentially pumped, heated quartz capillary. Mass traces for sulfur compounds, i.e. hydrogen sulphide, sulfur monoxide and sulfur dioxide, were measured but not observed during reaction testing. The sample was subjected to a temperature ramp of $5 \mathrm{~K} \mathrm{~min}^{-1}$ to $623 \mathrm{~K}$ and held for a pre-determined length of time $(0,3$, 6,12 and $24 \mathrm{~h}$ ), after which the reactant flows were halted, and the temperature cooled to ambient under the helium carrier gas.

In-situ temperature-programmed oxidation (TPO) studies of the samples were carried out post-reaction on the micro-reactor catalyst test line $[19,20]$. Oxygen $(5 \%$ in $\mathrm{He}$, $75 \mathrm{sccm}$, BOC Ltd, 99.5\%) was introduced to the sample and the reactor heated to $1173 \mathrm{~K}$ at $5 \mathrm{~K} \mathrm{~min}^{-1}$ using the mass spectrometer to monitor the eluting gases. In a previous investigation of FTO catalysts various masses were tested (20-40 mg) for in situ TPO measurements; catalyst charges $<40 \mathrm{mg}$ resulted in loss of a feature assigned to 'reactive carbon' (the $\alpha$ peak in Ref. [23]) and, furthermore, excessive carbon retention in the case of the promoted catalysts resulted in saturation of the oxidant making the measurements non-quantitative. As the TPO $\alpha$ peak is thought to be a key component in the catalyst conditioning phase [21], a mass of $40 \mathrm{mg}$ was utilised for measurements of the doubly promoted sample to ensure that all key components were observable [23]. Consequently, due to the oxygen demand of certain features exceeding the oxygen feed, the TPO profiles for the promoted catalyst are qualitative rather than quantitative, as has previously been the case [17-21]. The origins of these complications encountered in TPO measurements of FTO catalysts is thought to be an excessive degree of carbon laydown compared to $\mathbf{F e}$-ref.

\subsection{INS Reactor Measurements, Ambient Pressure CO Hydrogenation, $623 \mathrm{~K}$}

For INS measurements, approximately $10 \mathrm{~g}$ of catalyst was loaded into an Inconel reactor cell and attached to a custombuilt sample preparation rig [28]. For CO hydrogenation measurements, the doubly promoted iron oxide catalyst was heated to $623 \mathrm{~K}$ at $5 \mathrm{~K} \mathrm{~min}^{-1}$ under a flow of $\mathrm{CO}(75 \mathrm{sccm}$, CK Gas, $99.9 \%)$ and $\mathrm{H}_{2}(150 \mathrm{sccm}, \mathrm{CK}$ Gas, $99.9 \%)$ in a carrier gas (He, $600 \mathrm{sccm}$, CK Gas, $99.9 \%$, total WHSV of $\left.1.47 \mathrm{~h}^{-1}\right)$ and held at temperature for varying lengths of time $(3,6,12$ and $24 \mathrm{~h})$.

The gas products were analysed by an in-line mass spectrometer (Hiden Analytical, HPR20 QMS Sampling System). Once the specific reaction had finished, the reactant gases were stopped, and the sample cooled to room temperature under the helium carrier gas. The reactor cell was isolated and placed in an argon-filled glove box (MBraun UniLab MB-20-G, $\left[\mathrm{H}_{2} \mathrm{O}\right]<1 \mathrm{ppm},\left[\mathrm{O}_{2}\right]<2 \mathrm{ppm}$ ) before the sample was loaded into an aluminium sample holder that sealed via an indium wire gasket [28]. All INS measurements were performed using the MAPS direct geometry spectrometer [25]. Spectra were recorded at $20 \mathrm{~K}$ at incident neutron energies of $650 \mathrm{meV}$ and $250 \mathrm{meV}$ using the A-chopper package [28]. Quantification of the $\nu(\mathrm{C}-\mathrm{H})$ feature obtained by INS was achieved following a calibration protocol described elsewhere [17-23, 29].

\section{Results and Discussion}

\subsection{Micro-Reactor Measurements}

Characterisation and reaction performance of $\mathbf{F e}-\mathbf{N a}-\mathbf{S}_{\mathbf{1 0 0}}$, are reported elsewhere [23]. Figure 1a presents the qualitative TPO profiles for $\mathbf{F e}-\mathbf{N a}-\mathbf{S}_{\mathbf{1 0 0}}$ after reaction at 3, 6, 12 and $24 \mathrm{~h} \mathrm{T-o-S.} \mathrm{For} \mathrm{comparative} \mathrm{purposes,} \mathrm{the} \mathrm{corre-}$ sponding (quantitative) profiles for Fe-ref are presented alongside in Fig. 1b. Considering the reference catalyst in the first instance (Fig. 1b), 3 features are observable at $3 \mathrm{~h}$ T-o-S that are labelled $\alpha, \beta$ and $\gamma$. Following deductions presented elsewhere [21], the peaks are assigned as follows. The TPO $\alpha$ peak is attributed to 'reactive carbon'; this is thought to be a precursor species to formation of (i) the aliphatic component of the hydrocarbonaceous 

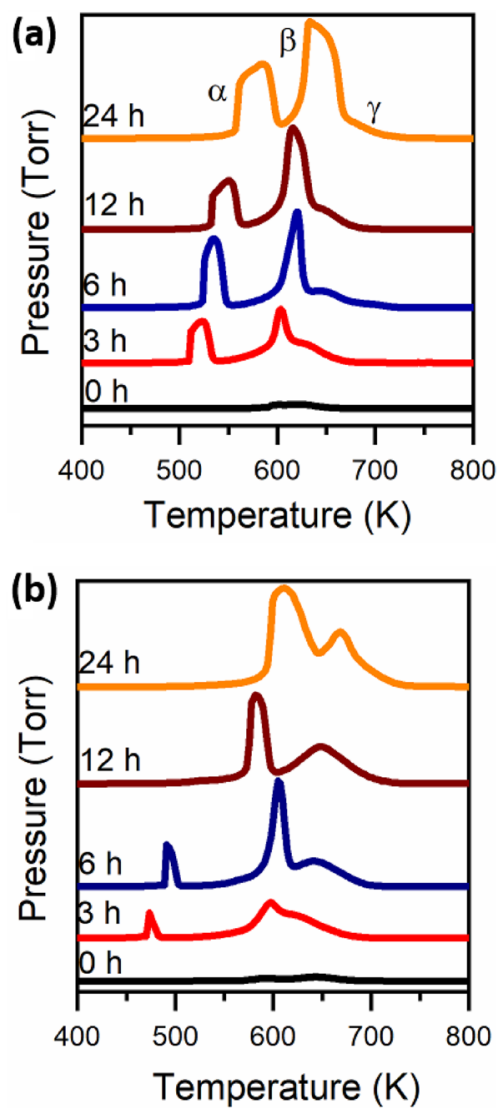

Fig. 1 a In situ TPO profiles of a doubly promoted iron catalyst with sulfur and sodium $\left(\mathbf{F e}-\mathbf{N a}-\mathbf{S}_{\mathbf{1 0 0}}\right)$ after exposure to ambient pressure $\mathrm{CO}$ hydrogenation conditions $\left(2: 1 \mathrm{H}_{2}: \mathrm{CO}\right.$ at $\left.623 \mathrm{~K}\right)$ for $0,3,6,12$ and $24 \mathrm{~h}$ T-o-S. b In situ TPO oxidation profiles of Fe-ref after exposure to ambient pressure $\mathrm{CO}$ hydrogenation conditions $\left(2: 1 \mathrm{H}_{2}: \mathrm{CO}\right.$ at 623 $\mathrm{K})$ for $0,3,6,12$ and $24 \mathrm{~h} \mathrm{T-o-S.} \mathrm{The} \mathrm{data} \mathrm{presented} \mathrm{in} \mathrm{(b)} \mathrm{has} \mathrm{been}$ reported previously by Warringham et al. [20] and is included in this figure for comparison purposes

overlayer, (ii) iron carbides and (iii) the TPO $\beta$ and/or $\gamma$ features. The TPO $\beta$ peak is attributed to amorphous carbon, whilst the $\gamma$ peak is assigned to contributions of iron carbide and polyaromatic carbonaceous species [21]. Figure $1 \mathrm{~b}$ shows the $\beta$ and $\gamma$ features to increase as a function of T-o-S, whereas the $\alpha$ feature is transitory, disappearing after $12 \mathrm{~h}$ T-o-S in the micro-reactor.

Figure 1a was recorded under the same conditions as Fig. 1b. However, Fe-Na-S $\mathbf{S}_{\mathbf{1 0 0}}$ displays a significantly different profile to that of Fe-ref. Firstly, the $\alpha$ peak is present throughout the full $24 \mathrm{~h}$ period examined. Secondly, its intensity relative to the $\beta$ feature is consistently enhanced, indicating a greater retention of this feature in the case of the promoted catalyst. On comparing the two profiles, it is suggested that the promoters are hindering the afore-mentioned catalyst conditioning process.
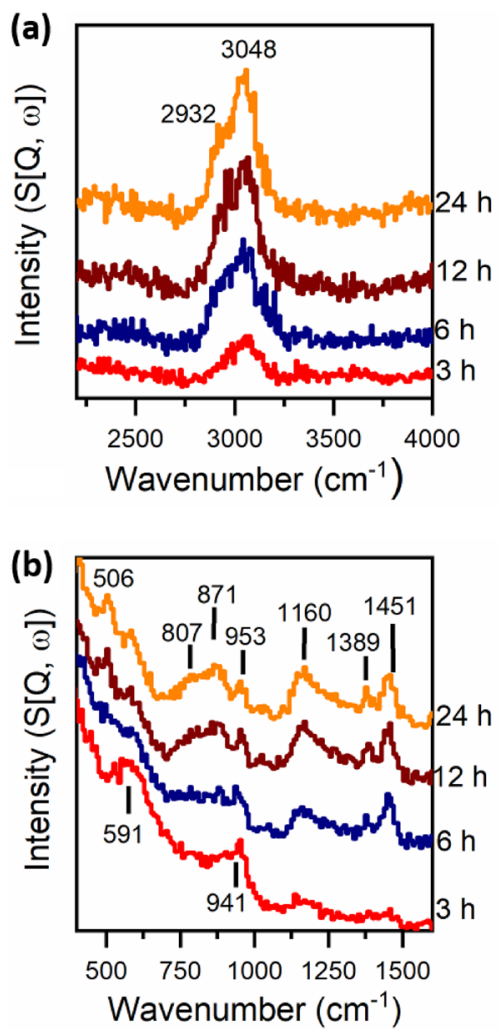

Fig. 2 INS spectra for an Fe-based doubly promoted FischerTropsch catalyst $\left(\mathbf{F e}-\mathbf{N a}-\mathbf{S}_{\mathbf{1 0 0}}\right)$ after continuous exposure to syngas $\left(\mathrm{CO}: \mathrm{H}_{2}=1: 2\right)$ at $623 \mathrm{~K}$ for $3-24 \mathrm{~h}$ : a incident energy $=650 \mathrm{meV}$; b incident energy $=250 \mathrm{meV}$. The spectra are stacked to facilitate comparison

\subsection{INS Measurements}

The post-reaction INS spectra are presented in Fig. 2. Figure $2 \mathrm{a}$ presents spectra in the $2200-4000 \mathrm{~cm}^{-1}$ region, whilst Fig. $2 b$ presents spectra in the range $400-1600 \mathrm{~cm}^{-1}$. Figure $2 \mathrm{a}$ shows progressive growth of $\nu(\mathrm{C}-\mathrm{H})$ modes as a function of T-o-S. The feature at $2932 \mathrm{~cm}^{-1}$ is assigned to the $\mathrm{sp}^{3}$ hybridised $\mathrm{C}-\mathrm{H}$ stretching mode, whilst the peak at $3048 \mathrm{~cm}^{-1}$ is attributed to $\mathrm{sp}^{2}$ hybridised $\mathrm{C}-\mathrm{H}$ stretching mode. The growth of these features is thought to signify an increasing presence of a hydrocarbonaceous overlayer. The spectra are more intricate in Fig. $2 b$ but, nonetheless, are indicative of predominately aromatic components with some aliphatic character. Each of the observed features for samples exposed to $\mathrm{CO}$ hydrogenation conditions $\geq 6 \mathrm{~h}$ have been observed previously for the Fe-ref sample and can be summarised as follows: $\mathrm{C}-\mathrm{C}$ torsion mode of edge carbon atoms contained within a polycyclic aromatic network $\left(506 \mathrm{~cm}^{-1}\right)$; out-of-plane $\mathrm{C}-\mathrm{H}$ deformation of either an olefinic or aromatic group $\left(871 \mathrm{~cm}^{-1}\right)$; alkenic $\delta(\mathrm{C}-\mathrm{H})$ $\left(953 \mathrm{~cm}^{-1}\right)$; $\mathrm{CC}-\mathrm{H}$ in plane deformation of a polyaromatic hydrocarbon $\left(1160 \mathrm{~cm}^{-1}\right)$ and methyl deformation modes 
$\left(1389,1451 \mathrm{~cm}^{-1}\right)[20,21]$. Overall, the INS spectrum for the FTO catalyst at $24 \mathrm{~h} \mathrm{T-o-S} \mathrm{(Fig.} \mathrm{2)} \mathrm{is} \mathrm{comparable} \mathrm{to}$ that previously reported for Fe-ref [20], signifying that the overall nature of the hydrocarbonaceous overlayer is broadly comparable for both classes of catalyst.

The sample exposed to $3 \mathrm{~h}$ on stream displays two prominent bands at 591 and $941 \mathrm{~cm}^{-1}$ that are respectively assigned to (i) the $\mathrm{A}_{1 \mathrm{~g}}$ phonon of $\mathrm{Fe}_{3} \mathrm{O}_{4}$ and (ii) a combination band from alkenic $\delta(\mathrm{C}-\mathrm{H})$ and a magnetic interaction associated with $\mathrm{Fe}_{3} \mathrm{O}_{4}$ [16-23, 30]. Thus, they are indicative of magnetite $\left(\mathrm{Fe}_{3} \mathrm{O}_{4}\right)$ and signify a degree of under reduction of the catalyst.

Utilising established calibration measurements [17-23, 29], each of the identified species observed in Fig. 2a, were quantified and the resulting hydrogen content profiles are presented in Fig. 3(a). For comparative purposes, the corresponding profile for Fe-ref is presented in Fig. 3b. Figure 3a shows comparable profiles for both the aliphatic $\left(2932 \mathrm{~cm}^{-1}\right)$ and olefinic/ aromatic $\left(3048 \mathrm{~cm}^{-1}\right)$ components of the hydrocarbonaceous overlayer, with saturation achieved in both cases at $\sim 12 \mathrm{~h} \mathrm{T-o-}$ S. In comparison, although Fig. $3 b$ shows Fe-ref to display a comparable profile in the case of the aliphatic component,
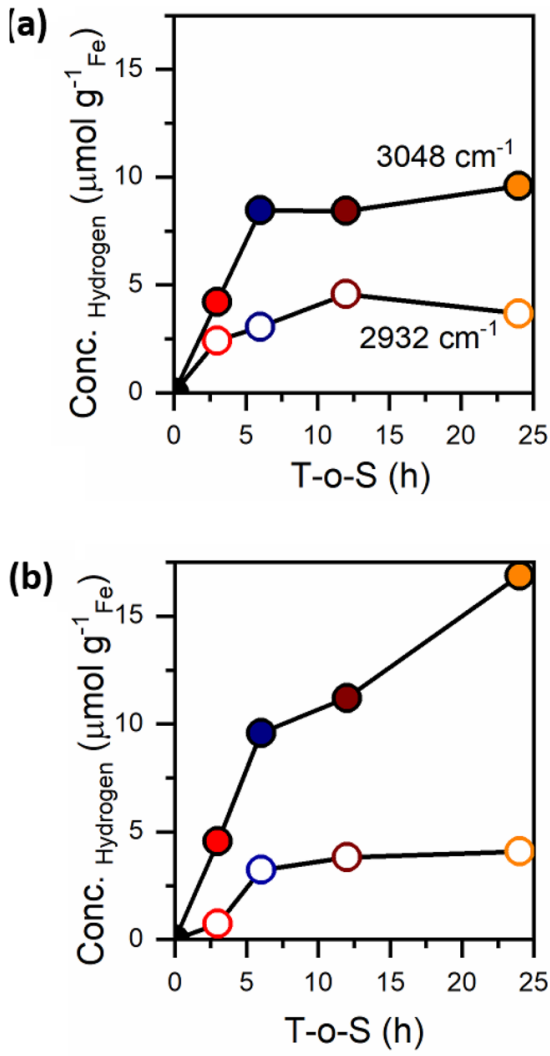

Fig. 3 Hydrogen content of $2932 \mathrm{~cm}^{-1}$ (hollow) and $3052 \mathrm{~cm}^{-1}$ (solid) features as a function of T-o-S: a Fe-Na-S $\mathbf{S}_{\mathbf{1 0 0}}$; $\mathbf{b}$ Fe-ref. The data presented in (b) has been reported previously by Warringham et al. [20] and is included in this figure for comparison purposes the olefinic/aromatic feature continues to develop throughout the full $24 \mathrm{~h}$ period. Clearly, the inclusion of the promoters is selectively perturbing the composition of the hydrocarbonaceous overlayer: The degree of laydown at $24 \mathrm{~h} \mathrm{T-o-S}$ is comparable for aliphatic moieties (unpromoted, $3.81 \mu \mathrm{mol} \mathrm{H}$ $\mathrm{g}_{\mathrm{Fe}}^{-1}$ vs. promoted, $3.68 \mu \mathrm{mol} \mathrm{H} \mathrm{g}_{\mathrm{Fe}}^{-1}$ ) but, in contrast, the aromatic component by $24 \mathrm{~h}$ has significantly diminished for the Fe-Na-S $\mathbf{1 0 0}_{\mathbf{1 0 0}}$ sample, $\left(\mathbf{F e}-\mathbf{N a}-\mathbf{S}_{\mathbf{1 0 0}}=9.58 \mu \mathrm{mol} \mathrm{H} \mathrm{g}_{\mathrm{Fe}}^{-1} ; \mathbf{F e}-\right.$ ref $=16.89 \mu \mathrm{mol} \mathrm{H} \mathrm{g}_{\mathrm{Fe}}^{-1}$ ).

The continued prominence of the TPO $\alpha$ peak in Fig. 1a at reaction times in excess of $12 \mathrm{~h} \mathrm{T-o-S}$ is interpreted as signifying that the sodium and sulfur are impeding the catalyst conditioning process. Further, it is possible that the coincidence of the relatively long-lived $\alpha$ peak and the attenuation of the $\mathrm{sp}^{2}$ hybridised hydrocarbon species (Fig. 3) is a reflection of the $\alpha$ peak's role as a precursor to the formation of those entities, with kinetic blocking (see below) of olefinic/aromatic entities leading to an accumulation of 'reactive carbon'.

It is informative to now consider the connectivity between the form of the hydrocarbonaceous overlayer and catalytic performance. Previous testing at elevated temperature and pressure confirm the FTO credentials of $\mathbf{F e}-\mathbf{N a - S _ { 1 0 0 }}$ [23]. So how may the dual promotion of the hematite be facilitating favourable $\mathrm{C}_{2}-\mathrm{C}_{4}$ olefin selectivity and reduced methane yields? Figure 3 indicates that the promoters are selectively attenuating the olefinic/aromatic component of the hydrocarbonaceous overlayer. Previous work from this group has considered a role for the hydrocarbonaceous overlayer in influencing hydrogen supply [20]. Specifically, the hydrocarbonaceous overlayer is thought to form over an active iron carbide phase. However, the coverage of the overlayer is partial, leaving distinct 'open' sites that are responsible for the dissociative adsorption of carbon monoxide and dihydrogen. Thus, the hydrocarbonaceous overlayer is effectively providing a template that defines reagent accessibility to the underlying iron carbide surface [20]. Within this scenario, the under-developed overlayer observed for the dual promoted catalyst $\left(\mathbf{F e}-\mathbf{N a}-\mathbf{S}_{\mathbf{1 0 0}}\right)$ is thought to lead to a reduction in the supply of chemisorbed hydrogen atoms via imperfect formation of the 'pockets' that define the sites for dihydrogen dissociative adsorption. This scenario tilts the product slate from saturated to unsaturated products, as is observed experimentally [23]. Moreover, continued hydrogen supply is a prerequisite for sustained $\mathrm{C}-\mathrm{C}$ chain propagation. A reduced hydrogen supply would additionally constrain chain length. Extending these concepts further, as outlined previously for FTS catalysis [20], a constrained hydrogen supply will additionally favour the formation of amorphous carbon, as indicated by Eq. 1 .

$\mathrm{nC}_{(\mathrm{ad})} \rightarrow \mathrm{C}_{(\text {poly })} \mathrm{n}$

where $\mathrm{C}_{(\mathrm{ad})}$ represents adsorbed carbon atoms and $\mathrm{C}_{(\text {poly })}$ represents polymerised carbonaceous entities. This 
perspective is relevant to FTO chemistry, where a perceived role for the alkali metal is to facilitate $\mathrm{CO}$ dissociation [23, 31], which will lead to further carbon deposition. Under conventional FTS operating conditions with a rich hydrogen supply, sustained C-C propagation and saturated products will prevail. However, in a FTO format, Eq. 1 will be operative, and one anticipates a relatively greater proportion of retained carbon. Figure 1 is generally consistent with this perspective. Given the commercial relevance of the FTO process, further work is required to explore the validity and relevance of the concepts considered here.

\section{Conclusions}

Ambient pressure $\mathrm{CO}$ hydrogenation over a doubly promoted FTO catalyst $\left(\mathbf{F e}-\mathbf{N a}-\mathbf{S}_{\mathbf{1 0 0}}\right)$ at $623 \mathrm{~K}$ has been investigated over a $24 \mathrm{~h}$ period and its performance compared to an unpromoted hematite sample (Fe-ref) examined previously. Characterisation of the catalyst post-reaction through TPO and INS has led to the following conclusions.

- TPO measurements show the $\alpha$ peak, assigned to 'reactive carbon', to prevail over the full $24 \mathrm{~h}$ period. This is interpreted as indicating that dual promotion of the hematite sample is hindering the catalyst conditioning process.

- INS spectroscopy shows the progressive formation of a hydrocarbonaceous overlayer with increasing T-o-S but that the development of the $\mathrm{sp}^{2}$ hybridised $\mathrm{C}-\mathrm{H}$ component is attenuated compared to that observed for the unpromoted hematite sample.

- The ability of FTO catalysts to display favourable selectivity towards low molecular weight olefins and reduced methane yields is tentatively attributed to the formation of an under-developed hydrocarbonaceous overlayer, which leads to a relatively constrained supply of surface hydrogen atoms.

Acknowledgements Sasol Ltd., the University of Glasgow and the EPSRC [award reference EP/P505534/1.] are thanked for the provision of a postgraduate studentship (ALD). The STFC Rutherford Appleton Laboratory is thanked for access to neutron beam facilities [DOI: https://doi.org/10.5286/ISIS.E.RB1610413 and https://doi.org/10.5286/ ISIS.E.RB1810122]. The Royal Society is thanked for the provision of an Industry Fellowship (PBW).

Data Availability The datasets generated during and/or analysed during the current study are available from the corresponding author on reasonable request.

\section{Declarations}

Conflict of interest The authors have no conflicts of interest.
Research Involving Human and/or Animal Participants There were no human or animal subjects involved in this research.

Open Access This article is licensed under a Creative Commons Attribution 4.0 International License, which permits use, sharing, adaptation, distribution and reproduction in any medium or format, as long as you give appropriate credit to the original author(s) and the source, provide a link to the Creative Commons licence, and indicate if changes were made. The images or other third party material in this article are included in the article's Creative Commons licence, unless indicated otherwise in a credit line to the material. If material is not included in the article's Creative Commons licence and your intended use is not permitted by statutory regulation or exceeds the permitted use, you will need to obtain permission directly from the copyright holder. To view a copy of this licence, visit http://creativecommons.org/licenses/by/4.0/.

\section{References}

1. Van de Loosdrecht J, Botes FG, Ciobica IM, Ferreira A, Gibson P, Moodley DJ, Saib AM, Visage JL, Weststrate CJ, Niemantsverdriet JW (2013) Comprehensive inorganic chemistry II. In: Reedijk J, Poeppelmeier KK (eds) Fischer-Tropsch synthesis: catalysts and chemistry. Elsevier, Oxford, pp 525-557

2. Botes GF, Bromfield TC, Coetzer RLJ, Crous R, Gibson P, Ferreira AC (2016) Development of a chemical selective iron Fischer Tropsch catalyst. Catal Today 275:40-48

3. Yuan Y, Huang S, Wang H, Wang Y, Wang J, Lv J, Li Z, Ma X (2017) Monodisperse nanon- $\mathrm{Fe}_{3} \mathrm{O}_{4}$ on $\alpha-\mathrm{Al}_{2} \mathrm{O}_{3}$ catalysts for Fischer-Tropsch synthesis to lower olefins: promoter and size effects. ChemCatChem 9:3144-3152

4. Galvis HMT, Koeken ACJ, Bitter JH, Davidian T, Ruitenbeek M, Dugulan AI, de Jong KP (2013) Effects of sodium and sulfur on catalytic performance of supported iron catalysts for the FischerTropsch synthesis of lower olefins. J Catal 303:22-30

5. Galvis HMT, Koeken ACJ, Bitter JH, Davidian T, Ruitenbeek M, Dugulan AI, de Jong KP (2013) Effect of precursor on the catalytic performance of supported iron catalysts for the FischerTropsch synthesis of lower olefins. Catal Today 215:95-102

6. Galvis HMT, de Jong KP (2013) Catalysts for production of lower olefins from synthesis gas: a review. ACS Catal 3:2130-2149

7. Paalanen PP, Weckhuysen BM (2020) Carbon pathways, sodiumsulphur promotion and identification of iron carbides in iron-based Fischer-Tropsch synthesis. ChemCatChem 12:4202-4223

8. Paalanen PP, van Vreeswijk SH, Weckhuysen BM (2020) Combined in situ X-ray powder diffractometry/Raman spectroscopy of iron carbide and carbon species evolution in $\mathrm{Fe}(-\mathrm{Na}-\mathrm{S}) / \alpha$ A12O3 catalysts during Fischer-Tropsch synthesis. ACS Catal 10:9837-9855

9. Paalanen PP, van Vreeswijk SH, Dugulan AI, Weckhuysen BM (2020) Identification of Iron Carbides in $\mathrm{Fe}(-\mathrm{Na}-\mathrm{S}) / \alpha-\mathrm{Al} 2 \mathrm{O} 3$ Fischer-Tropsch synthesis catalysts with X-ray powder diffractometry and Mössbauer absorption spectroscopy. ChemCatChem 12:5121-5139

10. McCue AJ, Anderson JA (2014) Sulfur as a catalyst promoter or selectivity modifier in heterogeneous catalysis. Catal Sci Technol 4:272-294

11. Jiang F, Zhang M, Liu B, Xu Y, Liu X (2017) Insights into the influence of support and potassium or sulfur promoter on ironbased Fischer-Tropsch synthesis: understanding the control of catalytic activity, selectivity to lower olefins, and catalyst deactivation. Catal SciTechnol 7:1245-1265 
12. Jiao F, Li J, Pan X, Xiao J, Li H, Ma H, Wei M, Pan Y, Zhou Z, Li M, Miao S, Li J, Zhu Y, Xiao D, He T, Yang J, Qi F, Fu Q, Bao $\mathrm{Z}$ (2016) Selective conversion of syngas to light olefins. Science 351:1065-1068

13. Zhou X, Ji J, Wang D, Duan X, Qian G, Chen D, Zhou X (2015) Hierarchical structured $\alpha-\mathrm{Al}_{2} \mathrm{O}_{3}$ supported S-promoted Fe catalysts for direct conversion of syngas to lower olefins. Chem Commun 51:8853-8856

14. Cheng Y, Lin J, Xu K, Wang H, Yao X, Pei Y, Yan S, Qiao M, Zong B (2016) Fischer-Tropsch synthesis to lower olefins over potassium-promoted reduced graphene oxide supported iron catalysts. ACS Catal 6:389-399

15. Zhu Y, Pan X, Jiao F, Li J, Yang J, Ding M, Han Y, Liu Z, Bao $X$ (2017) Role of manganese oxide in syngas conversion to light olefins. ACS Catal 7:2800-2804

16. Hamilton NG, Silverwood IP, Warringham R, Kapitán J, Hecht L, Webb PB, Tooze RP, Parker SF, Lennon D (2013) Vibrational analysis of an industrial Fe-based Fischer-Tropsch catalyst employing inelastic neutron scattering. Angew Chem Int Ed 52:5608-5611

17. Hamilton NG, Warringham R, Silverwood IP, Kapitán J, Hecht L, Webb PB, Tooze RP, Zhou W, Frost CD, Parker SF, Lennon D (2014) The application of inelastic neutron scattering to investigate $\mathrm{CO}$ hydrogenation over an Iron Fischer-Tropsch synthesis catalyst. J Catal 312:221-231

18. Warringham R, Hamilton NG, Silverwood IP, How C, Webb PB, Tooze RP, Zhou W, Frost CD, Parker SF, Lennon D (2015) The application of inelastic neutron scattering to investigate a hydrogen pre-treatment stage of an iron Fischer-Tropsch catalyst. Appl Catal A 489:209-217

19. Warringham R, McFarlane AR, MacLaren DA, Webb PB, Tooze RP, Taylor J, Ewings RA, Parker SF, Lennon D (2015) The application of inelastic neutron scattering to explore the significance of a magnetic transition in an iron-based Fischer-Tropsch catalyst that is active for the hydrogenation of CO. J Chem Phys 143:174703

20. Warringham R, Davidson AL, Webb PB, Tooze RP, Ewings RA, Parker SF, Lennon D (2019) Examining the temporal behaviour of the hydrocarbonaceous overlayer on an iron based Fischer-Tropsch catalyst. RSC Adv 9:2608-2617

21. Davidson AL, Webb PB, Tooze RP, Ewings RA, Parker SF, Lennon D (2020) Hydrogen partitioning as a function of time-onstream for an unpromoted iron-based Fischer-Tropsch synthesis catalyst applied to CO hydrogenation. Ind EngChemRes 59:52-60

22. Warringham R, Davidson AL, Webb PB, Tooze RP, Parker SF, Lennon D (2020) Perspectives on the effect of sulfur on the hydrocarbonaceous overlayer on iron Fischer-Tropsch catalysts. Catal Today 339:32-39

23. Davidson AL, Gibson E, Cibin G, van Rensburg H, Parker SF, Webb PB, Lennon D (2020) The application of inelatic neutron scattering to investiagte iron-based Fischer-Tropsch to olefins catalysis. J Catal 392:197-208

24. Albers PW, Lennon D, Parker SF (2017) Neutron scatteringapplications in biology, chemistry, and materials science. In: Fernandez-Alonso F, Price DL (eds) Ch. 5 Catalysis. Academic Press, Cambridge, pp 279-348

25. Parker SF, Lennon D, Albers PW (2011) Vibrational Spectroscopy with neutrons: a review of new directions. Appl Spect 65:1325-1341

26. Zachariou A, Hawkins A, Parker SF, Lennon D, Howe RF (2020) Neutron spectroscopy studies of methanol to hydrocarbons catalysis over ZSM-5. Catal Today. https://doi.org/10.1016/j.cattod. 2020.05.030

27. Schulz H (1999) Short history and present trends of FisherTropsch synthesis. App Catal A Gen 186:3-12

28. Warringham R, Bellaire D, Parker SF, Taylor J, Ewings RA, Goodway CM, Kibble M, Wakefield SR, Jura M, Dudman MP, Tooze RP, Webb PB, Lennon D (2014) Sample environment issues relevant to the acquisition of inelastic neutron scattering measurements of heterogeneous catalyst samples. J Phys: Conf Ser 554:012005

29. Silverwood IP, Hamilton NG, Laycock CJ, Staniforth JZ, Ormerod RM, Frost CD, Parker SF, Lennon D (2010) Quantification of surface species present on a nickel/alumina methane reforming catalyst. Phys Chem Chem Phys 12:3102-3107

30. Chamritski I, Burns G (2005) Infrared- and Raman-active phonons of magnetite, maghemite, and hematite: a computer simulation and spectroscopic study. J Phys Chem B 109:4965-4968

31. Ribeiro MC, Jacobs G, Davis BH, Cronauer DC, Kropf AJ, Marshall CL (2010) Fischer-Tropsch synthesis: an in-situ TPREXAFS/XANES investigation of the influence of group I alkali promoters on the local atomic and electronic structure of carburized iron/silica catalysts. J Phys Chem C 114:7895-7903

Publisher's note Springer Nature remains neutral with regard to jurisdictional claims in published maps and institutional affiliations. 